
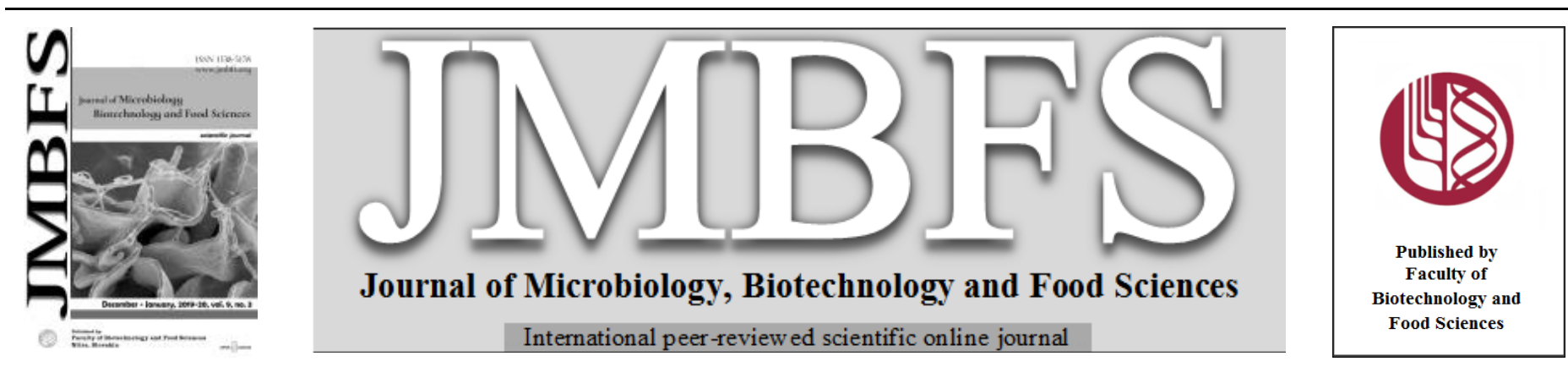

\title{
INSECTICIDAL AND REPELLENT ACTIVITIES OF EUCALYPTUS OIL AGAINST LESSER GRAIN BORER RHYZOPERTHA DOMINICA (FABRICIUS)
}

\author{
Rahul Kumar Chandel ${ }^{* 1,2}$, Suresh M. Nebapure ${ }^{2}$, Manju Sharma $^{1}$, S. Subramanian ${ }^{2}$, Chitra Srivastava², S.M. Paul Khurana ${ }^{1}$
}

Address(es):

${ }^{1}$ Amity Institute of Biotechnology, Amity University, Haryana, Gurgaon, Manesar-122413, India.

${ }^{2}$ Division of Entomology, Indian Agricultural Research Institute, New Delhi 110012, India.

*Corresponding author: rahulchandelbiotech@gmail.com

doi: $10.15414 / j m b f s .2019 / 20.9 .3 .525-529$

\section{ARTICLE INFO}

Received 9. 10. 2018

Revised 23. 5. 2019

Accepted 30. 5. 2019

Published 1. 12. 2019

Regular article OPEN $\partial_{\text {AcCESS }}$

\begin{abstract}
Lesser grain borer Rhyzopertha dominica (F.) is a destructive insect pest of stored grains. Both larvae and adults of the pest attack whole, sound grain and cause extensive damage. Larvae are internal feeders whereas adults are free living and bore into the commodity and can fly. Fumigation is the most useful and effective method to manage this insect pest. There are several insecticides available in the market to manage this pest but some insecticides have been banned because of environmental pollutions and for some insecticides this insect pest has developed resistance. Therefore efforts are required to find safe, effective and viable alternatives. Natural products are well known to have a range of useful biological properties against insect pests. Recently, there has been considerable interest in essential oils and extracts of medicinal and edible plant and herbs for the development of alternative insecticides and fumigants. This research was initiated to evaluate the fumigation toxicity and repellent action of Eucalyptus globulus Labill essential oil against adults of $R$. dominica. GC/MS analysis showed the major components of E. globulus essential oil as 1,8-cineole (22.35\%), $\alpha$-pinene (12.58\%) limonene $(4.01 \%)$, aristolene (3.35\%), p-cymene (3.25\%), trans-verbenol $(3.02 \%)$, isosativene $(2.85 \%)$, $\alpha$-myrcene $(2.15 \%)$ and terpinen-4-ol (2.10\%). Fumigation toxicity and repellent activity showed that as the concentration and exposure time increased the mortality and repellency also increased. Maximum repellency of $62.0 \%$ was observed at $0.32 \mu 1 / \mathrm{cm}^{2}$ concentration after 36 hours of exposure.
\end{abstract}

Keywords: Eucalyptus species, Fumigant toxicity, Insecticides and fumigants, Insect repellent activity, Lesser Grain Borer

\section{INTRODUCTION}

Increase in human population has led to several problems, especially in respect to food security. At present time, agriculture is facing challenge to produce more food and fibre to feed growing population. Although we have produced enough of food grains, but there is a huge gap between demand and supply ostensibly due to loss in food grains. Losses in grain will start from the field and continue during storage leading to extensive qualitative as well as quantitative loss (Metcalf and Metcalf 1993; Sedlasek et al., 2001) much of this is due to insect pest attack (WAGOV 2005). Globally, storage pests damage account to the extent of 10 $40 \%$ of stored agricultural crops (Raja et al., 2001). The bostrichid beetle lesser grain borer, Rhyzopertha dominica is a highly destructive primary pest of stored grains including cereals, seeds and dried fruit. This insect is now established in several East and West African countries following recent accidental introductions from its previously more limited indigenous range in meso-America (Golob 1988). Fumigation is the main strategy to manage the insect pests of stored grains. There are several insecticides reported for treating godown and containers and for managing stored product pests such as organophosphates and pyrethroids (Kao et al., 1992; Hashem et al., 2012; Hung et al., 1990). Methyl bromide and phosphine achieved great success in the management of these stored grain insect but methyl bromide is one of the substance responsible for ozone layer depletion and signatory countries of montreal protocol are being phasing out the production of such compounds and fumigation with phosphine has a long history of resistance development (Hashem et al., 2012; Collins et al., 2000; Tyler et al., 1983; Rajendran and Narasimhan 1994; Ren et al., 1994; Collins 1998; Acda 2000; Ansell et al., 1990). Although, fumigation is the only option for bulk storage of grains, there is limited scope of utilizing the fumigation technique for grain protection at small scale grain storage at farm sites in view of lack of trained manpower in conducting scientific fumigation and paraphernalia required for cover fumigation using toxic phosphine tablets. Hence, there is a need to develop alternative safe and economical non-chemical methods for controlling insect pests of stored products at small scale grain storage. Among the available options, essential oils and their constituents may have potential as alternative fumigants in view of their volatility and fumigant activities (Shaaya et al., 1997). Essential oils are usually obtained via steam distillation of medicinal and aromatic plants, mostly used as fragrance and flavouring agents for aromatherapy and as herbal medicines. Essential oils from more than seventy five plant species have been studied for fumigant toxicity against insect pests of stored grains (Rajendran and Sriranjini 2008). Among the essential oils, Eucalyptus oil is more useful as it is easily extractable and possesses a wide range of desirable properties worth exploiting for insect pests management Eucalyptus is a naturally-green, tall tree covered with odorous branches full of essence-based centers and found all over the world. The oil has been used commercially in food, flavoring, perfumery, and in the pharmaceutical industries (Aref et al., 2015; Singh et al., 2009). The essential oil from leaves of Eucalyptus species has been the object of several studies viz., antibacterial, antiinflammatory, antioxidant, anti-hyperglycemic, anti-malarial, antifungal and analgesic activity (Bendaoud et al., 2009; Gray and Flat 1998; Yu Chang et al., 2006) .Considering the dual global necessity to achieve food security and food safety, more attention should be devoted to explore novel alternative treatments that are economically feasible, sustainable, user and environment friendly. In the view of above mentioned facts, present study was undertaken to elucidate the constituents of Eucalyptus globulus (Family: Myrtaceae) essential oil and to evaluate its fumigation toxicity against lesser grain borer, $R$. dominica.

\section{MATERIAL AND METHODS}

\section{Collection and Culture of Insects}

Insect culture of Rhyzopertha dominica was procured from storage laboratory, Division of Entomology, Indian Agricultural Research Institute, New Delhi, India. About 200-400 adults were released in the $1 \mathrm{~L}$ glass container having 400 grams of wheat mixed with 5\% Brewer's yeast and jars were kept in rearing room maintained at $30+2{ }^{\circ} \mathrm{C}$ and $70 \%$ R.H. After four to five days of oviposition, these adults were separated and put into a fresh rearing jar. A succession of jars having 
four to five days oviposition in each was maintained. On emergence of appreciable number of adults, the insects were sieved out and used for experiment or subsequent sub-culturing.

\section{Essential oil}

The essential oil of E. globulus used in this study was obtained from Central Institute of Medicinal and Aromatic Plants (CIMAP), Pantnagar, Uttrakhand, India

\section{Chemical analysis of essential oil}

Gas Chromatography- Mass Spectroscopy (GC/MS) Analysis: The separation and identification of compounds in E. globulus essential oil was done by using Shimadzu QP 2010 Ultra GC-MS equipped with Rtx-5ms column measuring $30 \times 0.25 \mathrm{~mm}$ and NIST14 library. Helium with flow rate $1 \mathrm{ml} / \mathrm{min}$ was used as carrier gas. $1 \mu \mathrm{l}$ volume of each sample was utilized. The injection temperature was maintained at $250^{\circ} \mathrm{C}$. The oven temperature programme was set with initia temperature at $50^{\circ} \mathrm{C}$ and then it was increased to $250^{\circ} \mathrm{C}$ with $4^{\circ} \mathrm{C} / \mathrm{min}$ ramping rate. The temperature for ion source was maintained at $200^{\circ} \mathrm{C}$ and the interface at $250^{\circ} \mathrm{C}$.

\section{Fumigant toxicity}

To determine the fumigant toxicity of the E. globulus essential oil, flat bottom fumigation flasks of $250 \mathrm{ml}$ with airtight stopper were used. Thirty adult insects (1-7 days old) were released in glass vial covered with muslin cloth and kept at the bottom of flask. Concentrations i.e., 50, 100, 150, 200, 250 and $300 \mu \mathrm{L} / \mathrm{L}$ of E. globulus essential oil were applied. Essential oil at desired concentrations was applied onto a piece of filter paper (Whatman No.1) of $2.5 \mathrm{~cm}$ diameter size. The treated filter paper strip was hung inside the flask through a thread and then flask was tightly closed with a glass stopper. Untreated filter paper strips served as a control. The experiment was replicated five times and mortality was recorded a $3,6,9,12$ and $24 \mathrm{~h}$ after exposure. After completion of exposure period the flask were opened and vials kept outside for two hours at room temperature in norma conditions. Observations were recorded on mortality of the insects. The treated insects when primed with a camel hair brush would be considered dead when no leg or antennal movements were observed. Per cent mortality of adult insects was recorded after taking into account control mortality using the Abbott's correction (Abbott, 1925). Probit analysis was done to estimate the values of $\mathrm{LT}_{50}$ and $\mathrm{LT}_{99}$ (Finney 1971).

\section{Repellency of Essential oil}

In order to study repellent activity, an experiment was carried out in $10 \mathrm{~cm}$ diameter glass petri dishes following the method described by Jilani and Saxena (1990) with some modifications. Test solutions were prepared by dissolving 2,4 6 and $8 \mu \mathrm{l}$ of E. globulus essential oil in $1 \mathrm{ml}$ of acetone. The filter paper was cut into two equal pieces and each concentration was applied at half portion of filter paper uniform by using micro pipette. The other half of the filter paper was treated with acetone only as control. The treated halves were air-dried to evaporate the solvent completely. Treated and untreated halves were attached with tape and placed in petri dishes. Twenty adults of $R$. dominica were released at the center of the filter paper in petri dishes and then sealed firmly, each dose was replicated five times. The number of insects present on both the treated and untreated halves was recorded after 3, 6, 24, 36 hours.

Percentage repellency (PR) was calculated according to McDonald formula (McDonald et al., 1970) as follows:

$$
\mathrm{PR}=[(\mathrm{Nc}-\mathrm{Nt}) /(\mathrm{Nc}+\mathrm{Nt})] 100
$$

Where: Nc: Numbers of insects in the control filter paper area.

$\mathrm{Nt}$ : number of insects in the treated filter paper area.

\section{RESULTS AND DISCUSSION}

\section{Chemical composition of Eucalyptus globulus essential oil}

Fifty three compounds (Table 1) were identified in the E. globulus essential oil These include 1, 8-cineole $(22.35 \%), \alpha$-pinene $(12.58 \%)$, limonene $(4.01 \%)$, aristolene $(3.35 \%)$, p-cymene $(3.25 \%)$, trans-verbenol $(3.02 \%)$, isosativene $(2.85 \%), \alpha$-myrcene $(2.15 \%)$ and terpinen-4-ol $(2.10 \%)$ as major components Chemical composition of essential oils of different eucalyptus species have earlier been elucidated (Derwich et al., 2009; Bignell et al., 1996; Khemira et al., 2012). Among the chemical constituents of Eucalyptus oil, $\alpha$-pinene and 1,8cineole were identified as major components The insecticidal and repellency effects of 1,8-cineole, terpineol and $\alpha$-pinene have been demonstrated by other researchers too (Tapondjou et al ., 2005). Some researchers found 1,8-cineole to be highly repellent and toxic to Sitophilus granarius L., S. zeamais, Tribolium confusum and Prostephanus truncates (Horn) (Obeng Ofori et al., 1997). While, in some of the studies indicate that $\alpha$-pinene and terpineol to possess poten repellent and toxic effects against Tribolium confusum (Ojimelukwe and Adler
1999). Among various compounds of E. globulus essential oil, $\alpha$-pinene and1,8 cineole was found as major ones. This compound is characteristic of the Eucalyptus genus and is mainly attributed to its insecticidal properties (Batish et al., 2008). The above findings suggest that acute toxicity of $E$. globulus essential oil and its constituent compounds especially $\alpha$-pinene and 1,8-cineole are quite promising and have insecticidal and repellency effects against lesser grain borer R. dominica.

Table 1 Chemical compounds identified in chronological order using GCMS analysis of Eucalyptus globulus essential oil (major compounds are marked in bold form).

\begin{tabular}{|c|c|c|c|}
\hline Peak & Compounds & *RT (min) & Area (\%) \\
\hline 1 & Isoledene & 3.86 & 0.40 \\
\hline 2 & Humulene & 4.92 & 0.51 \\
\hline 3 & $\alpha$-Elemene & 5.95 & 1.10 \\
\hline 4 & 3-Carene & 6.05 & 0.95 \\
\hline 5 & $\alpha$-Pinene & 7.05 & 12.58 \\
\hline 6 & Ocimene & 7.12 & 0.30 \\
\hline 7 & $\alpha$-Terpinene & 7.25 & 0.40 \\
\hline 8 & $\alpha$-Cubebene & 7.38 & 0.50 \\
\hline 9 & Cis-ocimene & 7.80 & 0.80 \\
\hline 10 & Gama-Cadinene & 8.05 & 0.90 \\
\hline 11 & Camphene & 8.25 & 1.10 \\
\hline 12 & Epizonarene & 8.75 & 0.90 \\
\hline 13 & $\beta$-caryophyllene & 8.90 & 0.70 \\
\hline 14 & $\beta$-Pinene & 9.05 & 2.20 \\
\hline 15 & $\alpha$-Thujone & 9.12 & 1.10 \\
\hline 16 & Isocaryophillene & 9.45 & 1.10 \\
\hline 17 & Patchoulene & 9.75 & 0.08 \\
\hline 18 & Copaene & 9.87 & 1.20 \\
\hline 19 & Ylangene & 15.96 & 0.30 \\
\hline 20 & Seychellene & 18.02 & 1.10 \\
\hline 21 & 1,8-Cineole & 20.56 & 22.35 \\
\hline 22 & Isosativene & 21.12 & 2.85 \\
\hline 23 & Aristolene & 21.35 & 3.35 \\
\hline 24 & Solanone & 22.09 & 2.05 \\
\hline 25 & $\beta$-Phellandrene & 22.80 & 1.18 \\
\hline 26 & $\alpha-$ Myrcene & 23.22 & 2.15 \\
\hline 27 & Terpenehydrochlorite & 23.45 & 1.21 \\
\hline 28 & p-Cymene & 24.50 & 3.25 \\
\hline 29 & Terpenylformate & 25.72 & 1.20 \\
\hline 30 & Sabinene & 26.85 & 1.49 \\
\hline 31 & Limonene & 28.35 & 4.01 \\
\hline 32 & Bornyl acetate & 29.50 & 1.05 \\
\hline 33 & terpinyl acetate & 30.08 & 2.10 \\
\hline 34 & Neryl acetate & 30.65 & 1.10 \\
\hline 35 & $\alpha$-terpineol & 32.05 & 2.10 \\
\hline 36 & Terpinolene & 34.64 & 0.91 \\
\hline 37 & Trans-verbenol & 35.26 & 3.02 \\
\hline 38 & 4- Caranol & 36.50 & 0.19 \\
\hline 39 & Terpinen-4-ol & 37.74 & 2.10 \\
\hline 40 & 1-Octen-3-ol & 38.06 & 0.10 \\
\hline 41 & p-Meth-1-en-4-ol cis & 38.45 & 1.15 \\
\hline 42 & $\alpha$-Eudesmol & 39.15 & 0.17 \\
\hline 43 & Geraniol & 40.35 & 0.98 \\
\hline 44 & Linalyl acetate & 40.65 & 0.10 \\
\hline 45 & m- Mentha, 4-8 diene & 40.60 & 1.19 \\
\hline 46 & Geranyl acetate & 41.56 & 0.90 \\
\hline 47 & Carvacrol & 41.80 & 0.70 \\
\hline 48 & Linalool & 42.95 & 0.40 \\
\hline 49 & Terpinylisovalerate & 43.10 & 0.80 \\
\hline 50 & Cis-linalool oxide & 44.01 & 0.85 \\
\hline 51 & Piperitone & 48.40 & 0.10 \\
\hline 52 & Borneol & 49.50 & 0.10 \\
\hline 53 & Geraniol & 52.12 & 0.13 \\
\hline Total & & & 93.55 \\
\hline
\end{tabular}

The insecticidal property of many essential oils is mainly attributed to monoterpenes which are typically volatile and are lipophilic compounds that can penetrate into insects rapidly and interfere with their physiological functions. Due to their high volatility, they have fumigant and gaseous action which are very important in controlling the stored-product insects (Aref et al., 2015). Among various medicinal and aromatic plants, Eucalyptus possesses a wide range of desirable properties worth exploiting for pest management (Boland $\boldsymbol{e t}$ al., 1991; FAO 1995). In fact, eucalyptus oil has been known for hundreds of years as antibacterial, antifungicidal and antiseptic in nature (Kleinig and Kleinig 2006). Eucalyptus oil ranks superior in quality and has advantages over essential oil from other tree crops since it has multipurpose uses in perfumery, pharmaceutical and other industries (Boland $\boldsymbol{e t}$ al., 1991; FAO 1995). The essential oils of 
eucalyptus species comprise of metabolic compositions such as terpenoids and phenols that have toxic effects against stored product pests (Lee et al., 2004; Tapondjou et al., 2005).

\section{Fumigant toxicity}

Essential oil of E. globulus was found to be toxic to adults of $R$. dominica when evaluated for its fumigant toxicity. In all cases, considerable differences in mortality of insects to essential oil vapour were observed with different concentrations and exposure period. The lowest concentration $(50 \mu \mathrm{L} / \mathrm{L})$ yielded $80 \%$ mortality after 24 hours exposure. When concentration was increased to 100,150 and $200 \mu \mathrm{L} / \mathrm{L}$ insect mortality was also increased to $83.3,93.3$ and $96.6 \%$ respectively after 24 hours exposure. The present study corroborate with previous finding which demonstrated the bio-efficacy of essential oils against major stored product insect pests for example the essential oils from Eucalyptus camaldulensis, Eucalyptus intertexta and Eucalyptus sargentii against three major stored product beetles, Callosobruchus maculates (F.), Sitophilus oryzae (L.) and Tribolium castaneum and the mortality increased significantly with increasing concentration against 1 to 7 days old adults (Negahban and Moharramipour 2007).

In the present study fumigant effect of Eucalyptus globulus oil against Rhyzopertha dominica was found to be $17.72 \mu \mathrm{L} / \mathrm{L}$ and $58.31 \mu \mathrm{L} / \mathrm{L}$ air $\mathrm{LT}_{50}$ and $\mathrm{LT}_{95}$ respectively (Table 2). Rhyzopertha dominica mortality increased with exposure period of Eucalyptus globulus oil (fig 1a, 1b, 1c, 1d, 1e). Our finding are consistent with Negahban and Moharramipour (2007) observed $\mathrm{LC}_{50} 2.55$ and $3.97 \mu \mathrm{l} / 1$ air against $C$. maculatus, 6.93 and $12.91 \mu \mathrm{l} / 1$ for $S$. oryzae and 11.59 and $33.50 \mu \mathrm{l} / 1$ air for T. castaneum with Eucalyptus essential oils. Similar insecticidal effects of Lavandula stoechas L. essential oil against Tribolium castaneum Herbst, Lasioderma serricorne (F.) and Rhyzopertha dominica were recorded at different concentrations and exposure times $(24,48$ and $72 \mathrm{~h})$ by Ebadollahi et al., (2010).

(1a)

$50 \mu \mathrm{L} / \mathrm{L}$

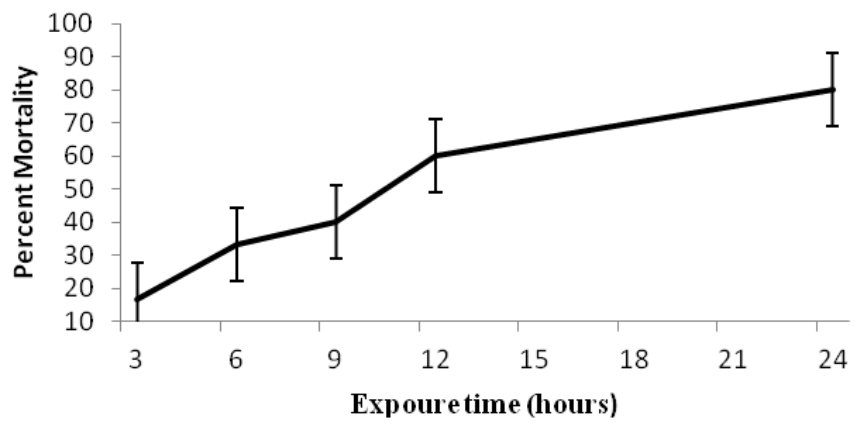

(1b)

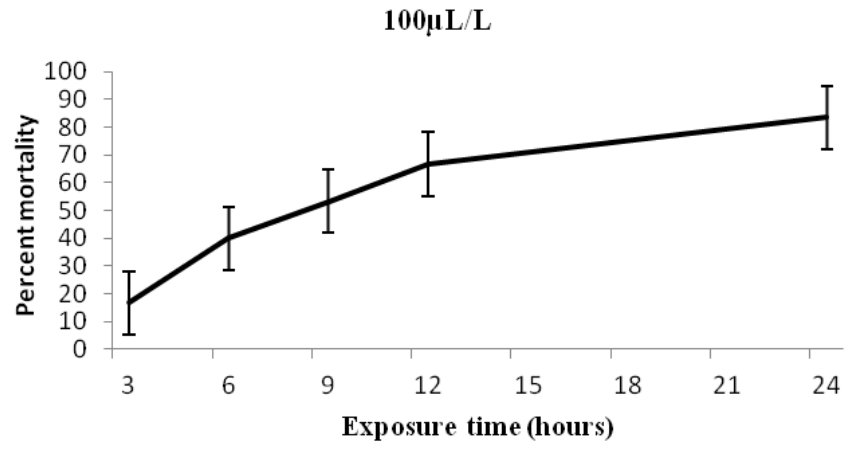

(1c)

$150 \mu \mathrm{L} / \mathrm{L}$

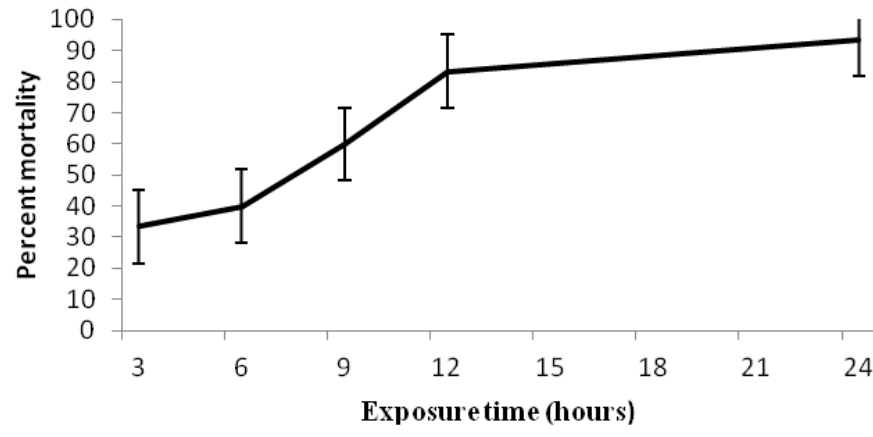

(1d)

$200 \mu \mathrm{L} / \mathrm{L}$

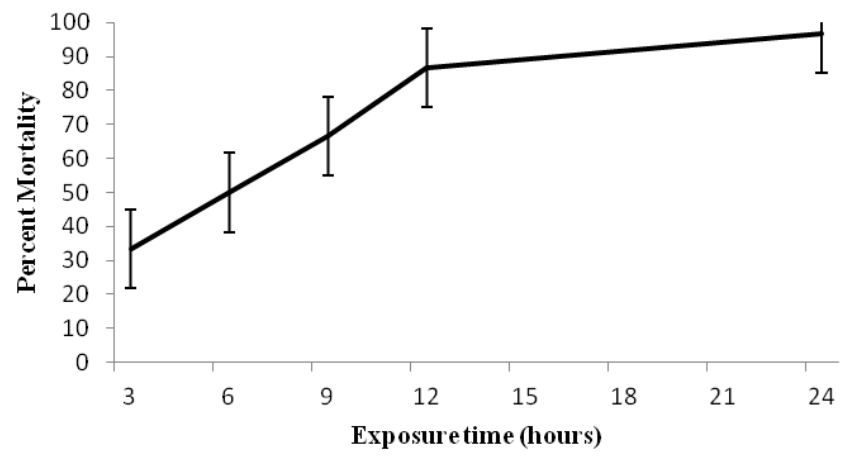

(1e)

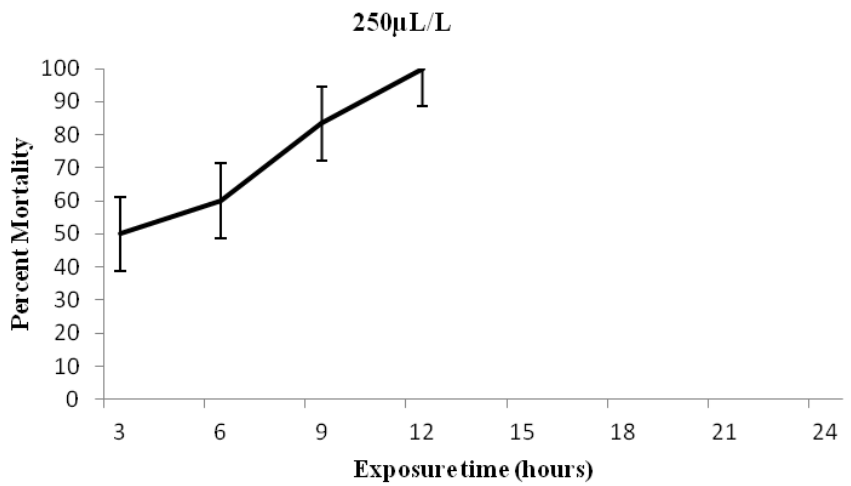

(1f)

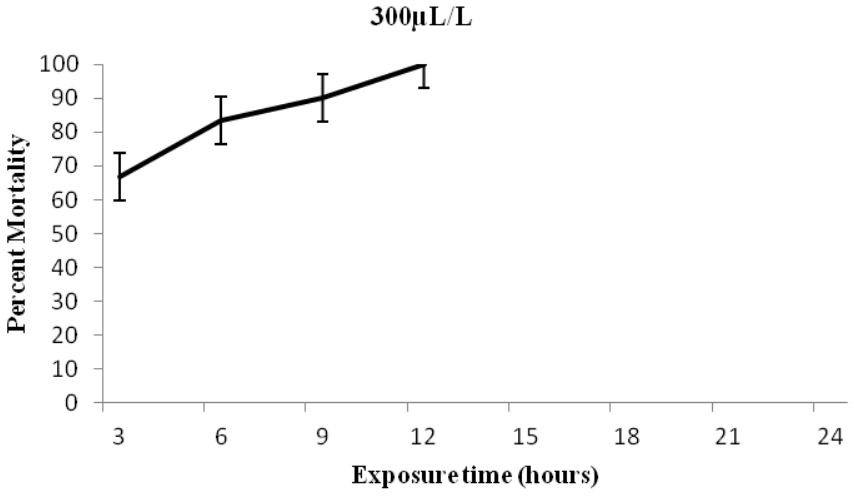

Figure 1a, 1b, 1c,1d, 1e,1f Percentage mortality of Rhyzopertha dominica exposed for various concentrations and exposure periods to Eucalyptus globulus essential oil at $27^{\circ} \mathrm{C}$ temperature and 65 percent relative humidity 
Table 2 Fumigation toxicity of Eucalyptus globulus oil against Rhyzopertha dominica

\begin{tabular}{|c|c|c|c|c|c|c|}
\hline $\operatorname{Dose}(\mu \mathrm{L})$ & $\mathbf{L T}_{50}(\mathrm{~h})(95 \% \mathrm{FL})$ & $\mathrm{LT}_{99}(\mathrm{~h})(\mathbf{9 5} \% \mathrm{FL})$ & Slope \pm SE & $\chi^{2}$ & DF & $\mathbf{H}$ \\
\hline 50 & $9.818(7.972-12.376)$ & $136.953(68.894-507.74)$ & $2.033 \pm 0.175$ & 4.0737 & 3 & 1.3579 \\
\hline 100 & $8.081(7.268-8.96)$ & $96.655(68.037-156.394)$ & $2.159 \pm 0.178$ & 0.702 & 3 & 0.234 \\
\hline 200 & $5.15(3.198-6.78)$ & $44.361(23.608-235.537)$ & $2.488 \pm 0.197$ & 10.463 & 3 & 3.487 \\
\hline 250 & $3.414(1.242-4.915)$ & $25.003(13.666-234.722)$ & $2.69 \pm 0.237$ & 13.909 & 3 & 4.636 \\
\hline 300 & $2.19(0.271-3.534)$ & $18.445(10.278-299.89)$ & $2.514 \pm 0.279$ & 11.358 & 3 & 3.786 \\
\hline
\end{tabular}

Abbreviations: FL- Fiducial Limits, DF- degree of freedom, H- heterogeneity, $\chi^{2}$ Chi-square. 95\% lower and upper fiducial limits are shown in parenthesis.

\section{Repellent activity}

The repellent activity of $E$. globulus essential oil against $R$. dominica was found to be both dose dependent and time dependent. At the lowest concentration 0.08 $\mu 1 / \mathrm{cm}^{2}$, the repellent activity was found to be $42.5 \%$ in 36 hours. When dose was increased to $0.16,0.24$, and $0.32 \mu \mathrm{l} / \mathrm{cm}^{2}$ the repellent activities were found to be $43.5,47.5$ and $62.5 \%$ respectively after 36 hours of exposure (Table 3 ). The repellent activity had increased with the increase in concentration and exposure period.

Table 3 Repellent activity per cent of Eucalyptus globulus essential oil against Rhyzopertha dominica

\begin{tabular}{|c|c|c|c|c|c|}
\hline & \multicolumn{5}{|c|}{ Repellent percent } \\
\hline \multirow[t]{2}{*}{$\begin{array}{l}\text { Insect } \\
\text { species }\end{array}$} & $\begin{array}{c}\text { Dose } \\
\left(\mu \mathrm{l} / \mathrm{cm}^{2}\right)\end{array}$ & & $\begin{array}{l}\text { Duration } \\
\text { exposure }\end{array}$ & & \\
\hline & & 3 & 6 & 24 & 36 \\
\hline \multirow{4}{*}{$\begin{array}{l}\text { Rhyzopertha } \\
\text { dominica }\end{array}$} & 0.08 & 17.5 & 35.0 & 41.00 & 42.5 \\
\hline & 0.16 & 32.0 & 40.0 & 42.5 & 43.5 \\
\hline & 0.24 & 38.5 & 42.0 & 45.5 & 47.5 \\
\hline & 0.32 & 40.0 & 53.5 & 60.5 & 62.5 \\
\hline
\end{tabular}

Role of essential oils from different plants have clearly been observed on various storage insects. In the present study chemical composition, fumigation toxicity and repellent activity of $E$. globulus essential oil was evaluated against the adults of Rhyzopertha dominica. The result revealed that E. globulus oil has significant repellency against $R$. dominica, similar finding was also observed by Salvadores et al., (2007) with clove essential oil against $R$. dominica, Sitophilus oryzae and $T$. castaneum and Benziet et al. (2009) against the adults of $S$. granarius, $R$. dominica, and $T$. castaneum by Schinus molle L. essential oils. In another experiment Khemira et $\boldsymbol{a l}$., (2012) reported the strong repellency of essential oil of E. astringens against $R$. dominica and Oryzaephilus surinamensis.

\section{CONCLUSIONS}

From this study, it is clear that E. globulus essential oil possess a wide spectrum of biological activities and having strong fumigant toxicity against $R$. dominica and provides a simple, cheap, and environment friendly alternative to pest control. Essential oils such as the one tested in this study can be commercially exploited as a fumigant for stored product insects and could be a potential candidate in the management of $R$. dominica and other stored product insect pests. However additional experiments are needed to exploit the individual effects of different constituents of essential oils of Eucalyptus sp. so as to augment ecofriendly methods of pest control in small grain storage structures.

Acknowledgments: Authors would like to thank the CSIR-Central Institute of Medicinal and Aromatic Plants, Pantnagar Uttrakhand, India for providing essential oil for the study.

Conflict of interest: The work is presented in the manuscript with the consent of all authors. The authors declare that they have no conflict of interest.

\section{REFERENCES}

Abbott, W. S. (1925). A method of computing the effectiveness of an insecticide. J. econ. Entomol, 18(2), 265-267.

Acda, M. A. (2000). Phosphine resistance in Rhyzopertha dominica (F.)(Coleoptera: Bostrychidae) from the Philippines(Doctoral dissertation, University of Queensland).

Ansell, M. R., Dyte, C. E., \& Smith, R. H. (1990, September). The inheritance of phosphine resistance in Rhyzopertha dominica and Tribolium castaneum. In Proc 5th Int Working Conf on Stored Product Protection, Bordeaux, France. Institut National de la Recherche Agronomique (pp. 961-969).

Aref, S. P., Valizadegan, O., \& Farashiani, M. E. (2015). Eucalyptus dundasii Maiden essential oil, chemical composition and insecticidal values against Rhyzopertha dominica (F.) and Oryzaephilus surinamensis (L.). Journal of Plant Protection Research, 55(1), 35-41.https://doi.org/ 10.1515/jppr-2015-0005
Bendaoud, H., Bouajila, J., Rhouma, A., Savagnac, A., \& Romdhane, M. (2009). GC/MS analysis and antimicrobial and antioxidant activities of essential oil of Eucalyptus radiata. Journal of the Science of Food and Agriculture, 89(8), 1292 1297. https://doi.org/10.1002/jsfa.3585

Batish, D. R., Singh, H. P., Kohli, R. K., \& Kaur, S. (2008). Eucalyptus essential oil as a natural pesticide. Forest Ecology and Management, 256(12), 2166-2174. https://doi.org/10.1016/j.foreco.2008.08.008

Benzi, V. S., Stefanazzi, N., \& Ferrero, A. A. (2009). Biological activity of essential oils from leaves and fruits of pepper tree (Schinus molle L.) to control rice weevil (Sitophilus oryzae L.).

Boland, D. J., Brophy, J. J., \& House, A. P. N. (1991). Eucalyptus leaf oils: use, chemistry, distillation and marketing.

Bignell, C. M., Dunlop, P. J., Brophy, J. J., \& Jackson, J. F. (1996). Volatile leaf oils of some South-western and Southern Australian species of the genus Eucalyptus. Part VII. Subgenus Symphyomyrtus, Section Exsertaria. Flavour and fragrance journal, 11(1), 35-41.

Collins, P. J., Daglish, G. J., Bengston, M., Lambkin, T. M., \& Pavic, H. (2002) Genetics of resistance to phosphine in Rhyzopertha dominica (Coleoptera: Bostrichidae). Journal of Economic Entomology, 95(4), 862-869. https://doi.org/10.1603/0022-0493-95.4.862

Collins, P. J. (1998, May). Resistance to grain protectants and fumigants in insect pests of stored products in Australia. In Proceedings of the Australian Postharvest Technical Conference (pp. 55-57). CSIRO, Canberra, Australia.

Derwich, E., Benziane, Z., \& Boukir, A. (2009). GC/MS analysis of volatile constituents and antibacterial activity of the essential oil of the leaves of Eucalyptus globulus in Atlas Median from Morocco. Advances in Natural and Applied Sciences, 3(3), 305-314. https://doi.org/10.3390/molecules21121671

Ebadollahi, A., Safaralizadeh, M., \& Pourmirza, A. (2010). Fumigant toxicity of Lavandula stoechas L. oil against three insect pests attacking stored products. Journal of Plant Protection Research, 50(1), 56-60 https://doi.org/10.2478/v10045-010-0010-8

Food And Agriculture Organization FAO 2013. Crop prospects and Food Situation. www.fao.org/docrep/019/aq119e/aq119e.pdf

FAO 1995. Eucalyptus oil. Chapter 5. In: Flavour and Fragrances of Plant Origin. Food and Agriculture Organization of the United Nations, Rome, Italy. Available online at http://www.fao.org/docrep/v5330e/V5350e07.htm (accessed on June 12, 2008).

Finney, D. J. (1971). Probit analysis, 3rd edn Cambridge. UK: University Printing House.

Gray, A. M., \& Flatt, P. R. (1998). Antihyperglycemic actions of Eucalyptus globulus (Eucalyptus) are associated with pancreatic and extra-pancreatic effects in mice. The journal of nutrition, 128(12), 2319-2323. https://doi.org/10.1093/jn/128.12.2319

Golob, P. (1988). Current status of the larger grain borer Prostephanus truncatus (Horn) in Africa. International Journal of Tropical Insect Science, 9(6), 737-745. https://doi.org/10.1017/S1742758400005622

Hashem, M. Y., Risha, E. S. M., El-Sherif, S. I., \& Ahmed, S. S. (2012). The effect of modified atmospheres, an alternative to methyl bromide, on the susceptibility of immature stages of angoumois grain moth Sitotroga cerealella (Olivier)(Lepidoptera: Gelechiidae). Journal of stored products research, 50, 5761. https://doi.org/10.1016/j.jspr.2012.05.003

Hung, C. C., Hsieh, F. K., \& Hwang, J. S. (1990). Stored grain insects monitoring and their chemical control. Chinese Journal of Entomology, 10(2), 169-179.

Kao, S. S., \& Tzeng, C. C. (1992). A survey of the susceptibility of rice moth (Corcyra cephalonica) and Angoumois grain moth (Sitotroga cerealella) to malathion and phoxim. Chinese Journal of Entomology, 12(4), 239-245.

Kleinig, D., \& Kleinig, D. (2006). Field Guide to Eucalypts. Vol. 1, Southeastern Australia. Bloomings Books.

Khemira, S., Mediouni-Ben Jemâa, J., Haouel, S., \& Khouja, M. L. (2012, March). Repellent activity of essential oil of Eucalyptus astringens against Rhyzopertha dominica and Oryzaephilus surinamensis. In International symposium on Medicinal and Aromatic Plants-SIPAM 2012997 (pp. 207-213). https://doi.org/10.17660/ActaHortic.2013.997.25

Lee, B. H., Annis, P. C., \& Choi, W. S. (2004). Fumigant toxicity of essential oils from the Myrtaceae family and 1, 8-cineole against 3 major stored-grain insects. Journal of Stored Products Research, 40(5), 553-564. https://doi.org/10.1016/j.jspr.2003.09.001 
Metcalf, R. L. (1993). Metcalf, RA Destructive and Useful Insects Their Habits and Control.

McDonald, L. L., Guy, R. H., \& Speirs, R. D. (1970). Preliminary evaluation of new candidate materials as toxicants, repellents, and attractants against storedproduct insects-1. Preliminary evaluation of new candidate materials as toxicants, repellents, and attractants against stored-product insects-1., (882).

Negahban, M., \& Moharramipour, S. (2007). Fumigant toxicity of Eucalyptus intertexta, Eucalyptus sargentii and Eucalyptus camaldulensis against storedproduct beetles. Journal of Applied entomology, 131(4), 256-261. https://doi.org/10.1111/j.1439-0418.2007.01152.x

Obeng-Ofori, D., Reichmuth, C. H., Bekele, J., \& Hassanali, A. (1997). Biological activity of 1, 8 cineole, a major component of essential oil of Ocimum kenyense (Ayobangira) against stored product beetles. Journal of Applied Entomology, 121(1-5), 237-243.https://doi.org/10.1111/j.14390418.1997.tb01399.x

Ojimelukwe, P. C., \& Adler, C. (1999). Potential of zimtaldehyde, 4-allyl-anisol, linalool, terpineol and other phytochemicals for the control of the confused flour beetle (Tribolium confusum J. d. V.)(Col., Tenebrionidae). Anzeiger für Schädlingskunde Journal of pest science, 72(4), 81-86. https://doi.org/10.1007/BF02768913

Rajendran, S., \& Sriranjini, V. (2008). Plant products as fumigants for storedproduct insect control. Journal of stored products Research, 44(2), 126-135. https://doi.org/10.1016/j.jspr.2007.08.003

Raja, N., Albert, S., Ignacimuthu, S. E., \& Dorn, S. (2001). Effect of plant volatile oils in protecting stored cowpea Vigna unguiculata (L.) Walpers against Callosobruchus maculatus (F.)(Coleoptera: Bruchidae) infestation. Journal of Stored Products Research, 37(2), 127-132. https://doi.org/10.1016/S0022474X(00)00014-X

Rajendran, S., \& Narasimhan, K. S. (1994). Phosphine resistance in the cigarette beetle Lasioderma serricorne (Coleoptera: Anobiidae) and overcoming control failures during fumigation of stored tobacco. International journal of pest management, 40(2), 207-210. https://doi.org/10.1080/09670879409371883

Ren, Y .L., O'brien, I. G., Whittle, G. P. (1994). Studies on the effect of carbon dioxide in insect treatment with phosphine. Stored Products Protection, Proceeding of the 6th International Conference on Stored Product Protection, Canberra. CAB, Wallingford, UK.pp 173-177.

Sedlacek, J. D., Komaravalli, S. R., Hanley, A. M., Price, B. D., \& Davis, P. M. (2001). Life history attributes of Indian meal moth (Lepidoptera: Pyralidae) and Angoumois grain moth (Lepidoptera: Gelechiidae) reared on transgenic corn kernels. Journal of economic entomology, 94(2), 586-592. https://doi.org/10.1603/0022-0493-94.2.586

Shaaya, E., Kostjukovski, M., Eilberg, J., \& Sukprakarn, C. (1997). Plant oils as fumigants and contact insecticides for the control of stored-product insects. Journal of Stored Products Research, 33(1), 7-15 https://doi.org/10.1016/S0022-474X(96)00032-X

Singh, H. P., Mittal, S., Kaur, S., Batish, D. R., \& Kohli, R. K. (2009). Characterization and antioxidant activity of essential oils from fresh and decaying leaves of Eucalyptus tereticornis. Journal of agricultural and food chemistry, 57(15), 6962-6966. https://doi.org/10.1021/jf9012407

Salvadores, Y. U., Silva, G. A., Tapia, M. V., \& Hepp, R. G. (2007). Spices powders for the control of maize weevil, Sitophilus zeamais Motschulsky, in stored wheat. Agricultura Tecnica, 67(2), 147-154.

Tapondjou, A. L., Adler, C., Fontem, D. A., Bouda, H., \& Reichmuth, C. H. (2005). Bioactivities of cymol and essential oils of Cupressus sempervirens and Eucalyptus saligna against Sitophilus zeamais Motschulsky and Tribolium confusum du Val. Journal of Stored Products Research, 41(1), 91-102. https://doi.org/10.1016/j.jspr.2004.01.004

Tyler, P. S., Taylor, R. W., \& Rees, D. P. (1983). Insect resistance to phosphine fumigation in food warehouses in Bangladesh. International Pest Control.

Western Australian Government Wagov (2005). Insect Pests of Stored Grains. www.agric.wa.gov.au crops post-harvest handling.

Yu Chang, S., Lung, H. O. C., Wang, E. I. C., Chang, S., T. (2006). Antifungal Activities and Chemical Compositions of Essential Oils from Leaves of Four Eucalypts. Taiwan Journal of Forest Science 21(1):49-61. 